\title{
Accurate Evaluation of the Specific Heat Capacity of Solids and its Application to $\mathrm{MgO}$ and $\mathrm{ZnO}$ Crystals
}

\author{
B. A. Mamedov • E. Eser • H. Koç • I. M. Askerov
}

Received: 3 December 2008 / Accepted: 15 May 2009 / Published online: 2 June 2009

(C) The Author(s) 2009. This article is published with open access at Springerlink.com

\begin{abstract}
Using binomial coefficients, new, simple, and efficient algorithms are presented for the accurate and fast calculation of the heat capacity of solids depending on the Debye temperature. As will be seen, the present formulation yields compact, closed-form expressions which enable the straightforward calculation of the heat capacity of solids for arbitrary temperature values. Finally, the algorithm is used to simulate the variation of the specific heat capacity with temperature of $\mathrm{MgO}$ and $\mathrm{ZnO}$ crystals. The results were compared with those reported in the literature and found to be in close agreement with those of other studies.
\end{abstract}

Keywords Binomial coefficient - Debye function - Specific heat capacity

\section{Introduction}

Debye functions are widely used in the study of many physical problems, especially in the evaluation of the heat capacity of solids [1-21]. A knowledge of the heat capacity of a substance not only provides essential insight into its vibrational properties but is also mandatory for many applications $[4,22,23]$. In the literature, various efficient numerical methods have been proposed for improving the evaluation of the $n$-dimensional Debye function, Debye temperature, and other types of Debye functions [10-13].

\footnotetext{
B. A. Mamedov $(\varangle) \cdot$ E. Eser · H. Koç · I. M. Askerov

Department of Physics, Faculty of Arts and Sciences, Gaziosmanpasa University, Tokat, Turkey e-mail: bamamedov@yahoo.com

E. Eser

e-mail: erhaneser06@yahoo.com

H. Koç

e-mail: huseyinnkoc@hotmail.com
} 
An accurate evaluation of the $n$-dimensional Debye function gives the Debye temperature of solids, which defines a boundary between the quantum-mechanical and classical behavior of phonons [24-26]. Debye functions can also be used in the computation of heat capacities of solids using Tarasov equations [6].

The aim of the study is to present an analytical expression to simplify the calculation of heat capacity in terms of an $n$-dimensional Debye function in any temperature range using the binomial coefficients [27]. The method is tested as an accurate and valid method for calculation of Debye functions of solids by applying it to $\mathrm{ZnO}$ and MgO samples [14,28-35].

\section{Expression for Specific Heat Capacity and its Application to $\mathrm{MgO}$ and $\mathrm{ZnO}$ Crystals}

Under the Debye approximation, the heat capacity per unit volume at constant volume is given by [4]

$$
C_{v}=3 N k L_{\mathrm{V}}\left(\frac{\theta}{T}\right)
$$

where $N$ is the Avogadro number, $k$ is the Boltzmann constant, $\theta$ is the Debye temperature of solids, and $T$ is the absolute temperature. In Eq. 1, the quantity $L_{V}(x)$ is defined as

$$
\begin{aligned}
L_{V}(x) & =3\left(\frac{T}{\theta}\right)^{3} \int_{0}^{x_{\mathrm{D}}} \frac{x^{4} \mathrm{e}^{x}}{\left(\mathrm{e}^{x}-1\right)^{2}} \mathrm{~d} x \\
& =3\left(\frac{T}{\theta}\right)^{3} I_{4}\left(2, x_{\mathrm{D}}\right)
\end{aligned}
$$

where $x_{D}=\frac{\theta}{T}$. The quantities $I_{n}\left(s, x_{\mathrm{D}}\right)$ occurring in Eq. $2 \mathrm{~b}$ are generally defined as

$$
I_{n}\left(s, x_{\mathrm{D}}\right)=\int_{0}^{x_{\mathrm{D}}} \frac{x^{n} \mathrm{e}^{x}}{\left(\mathrm{e}^{x}-1\right)^{s}} \mathrm{~d} x .
$$

We put $\mathrm{e}^{x}=t$ in Eq. 3 and obtain

$$
I_{n}\left(s, x_{\mathrm{D}}\right)=\int_{1}^{\mathrm{e}^{x_{\mathrm{D}}}} \frac{[\ln (t)]^{n}}{(t-1)^{s}} \mathrm{~d} t .
$$

For the evaluation of Eq. 4, we use the following binomial expansion theorem for an arbitrary real $n$ and $|x|>|y|$ (see $[13,36])$ : 


$$
(x \pm y)^{n}=\sum_{m=0}^{\infty}( \pm 1)^{m} F_{m}(n) x^{n-m} y^{m}
$$

where $F_{m}(n)$ is the binomial coefficient. Substituting Eq. 5 into Eq. 4, we obtain for $I_{n}\left(s, x_{\mathrm{D}}\right)$ integrals the following series formulae:

$$
I_{n}\left(s, x_{\mathrm{D}}\right)=\lim _{N \rightarrow \infty} \sum_{m=0}^{N}(-1)^{m} F_{m}(-s) H_{n m}\left(s, x_{\mathrm{D}}\right)
$$

where

$$
H_{n m}\left(s, x_{\mathrm{D}}\right)=\int_{1}^{\mathrm{e}^{x_{\mathrm{D}}}}[\ln (t)]^{n} t^{-s-m} \mathrm{~d} t
$$

In order to derive the formulas for Eq. 7, we use the partial integration method. Then, finally we obtain

$$
\begin{aligned}
H_{n m}\left(s, x_{\mathrm{D}}\right) & =\frac{n !\left[1-\mathrm{e}^{-x_{\mathrm{D}} w}\left\{1+x_{\mathrm{D}} w+\frac{1}{2 !} x_{\mathrm{D}}^{2} w^{2} \ldots \ldots\right\}\right]}{w^{n+1}} \\
& =n !\left[1-\mathrm{e}^{-x_{\mathrm{D}} w}\left(\sum_{k=0}^{n} \frac{\left(x_{\mathrm{D}} w\right)^{k}}{k !}\right)\right] w^{-(n+1)}
\end{aligned}
$$

where $w=m+s-1$. Taking into account Eq. 6 in Eq. 1, we obtain for the specific heat capacity the following simply structured formulae:

$$
C_{v}=9 N k\left(\frac{T}{\theta}\right)^{3} \lim _{L \rightarrow \infty} \sum_{m=0}^{L}(-1)^{m} F_{m}(-2) H_{4 m}\left(2, x_{\mathrm{D}}\right) .
$$

Considering Eq. 8 for $w=m+s$ and the binomial coefficients, we obtain for Debye functions the following formulae:

$$
D_{n}\left(s, x_{\mathrm{D}}\right)=\frac{n}{x_{\mathrm{D}}^{n}} \lim _{M \rightarrow \infty} \sum_{m=0}^{M}(-1)^{m} F_{m}(-s) H_{n m}\left(s, x_{\mathrm{D}}\right) .
$$

In Eqs. 6,9, and 10, the indices $N, L$, and $M$ are the upper limits of summations, respectively.

In order to demonstrate the accuracy and efficiency of the derived method, we have presented a comparison of numerical results using alternative methods (see Table 1). The validity and reliability of the method is then tested by applying it to $\mathrm{ZnO}$ and $\mathrm{MgO}$ crystals [14,31]. The temperature dependence of the specific heat capacity of $\mathrm{ZnO}$ and $\mathrm{MgO}$ crystals using our obtained formula, Eq. 9, are investigated. Debye temperatures $\theta$ for $\mathrm{ZnO}$ and $\mathrm{MgO}$ crystals have been taken as $920 \mathrm{~K}$ and $946 \mathrm{~K}$, respectively $[37,38]$. 


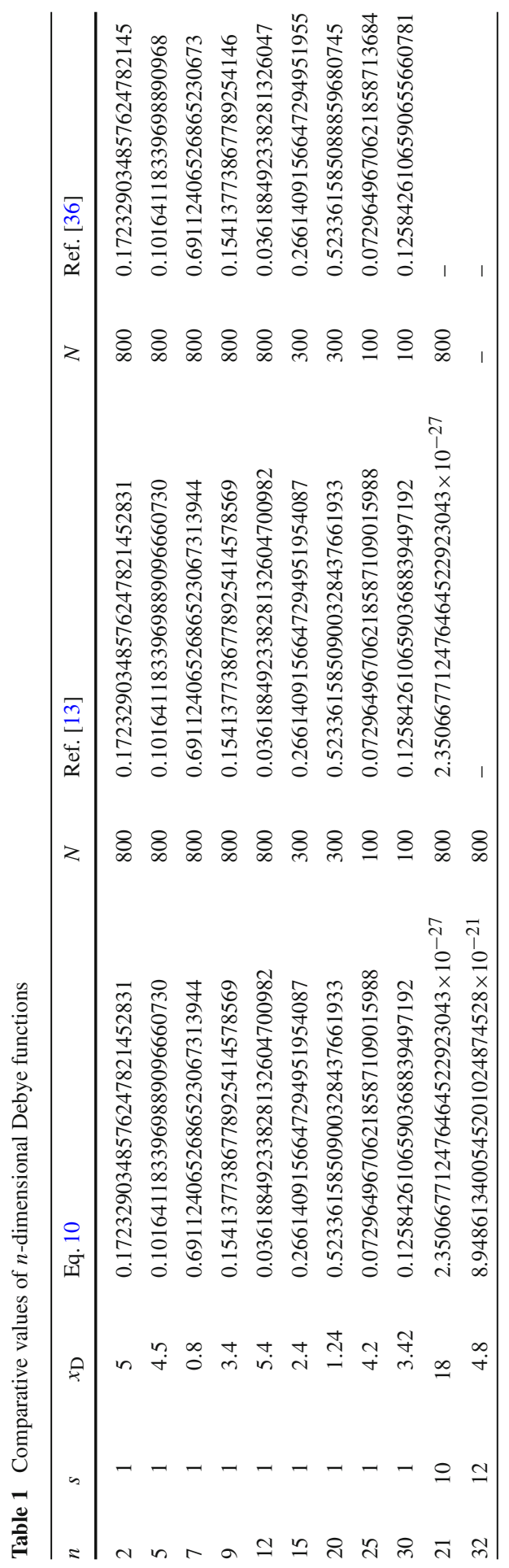




\section{Numerical Results and Discussion}

Firstly, the Mathematica software system (Version 5.0) was used to calculate Debye functions using the formulae presented in this study. The results obtained for Debye functions are shown in Table 1. In order to demonstrate the accuracy and efficiency of the methods described above, Table 1 also includes values obtained from other studies $[13,36]$. For comparison with studies by other authors, the $n$-dimensional Debye functions are derived using formulas given in Refs. [13] and [36]. Table 1 demonstrates excellent agreement between our results and those of Refs. [13] and [36]. This clearly demonstrates that the formulae obtained yield significant accuracy for arbitrary values of $n, s, x_{\mathrm{D}}$.

The variation of the specific heat capacity $C_{\mathrm{v}}$ against temperature $(T)$ of $\mathrm{ZnO}$ and $\mathrm{MgO}$ crystals are shown in Figs. 1 and 2 for the temperature range from $0 \mathrm{~K}$ to $2,100 \mathrm{~K}$. Figures 1 and 2 also illustrate the comparison of our results with those of Seko et al. [31] and $\mathrm{Lu}$ et al. [14] for $\mathrm{MgO}$ and $\mathrm{ZnO}$ samples.

From Fig. 1, it is shown that our results for $\mathrm{MgO}$ crystals are in excellent agreement with the results of Seko et al. [31]. Our results are also in agreement with those of Lu et al. [14], particularly in the temperature ranges, $(50 \mathrm{~K}$ to $300 \mathrm{~K})$ and $(700 \mathrm{~K}$ to $2,100 \mathrm{~K})$.

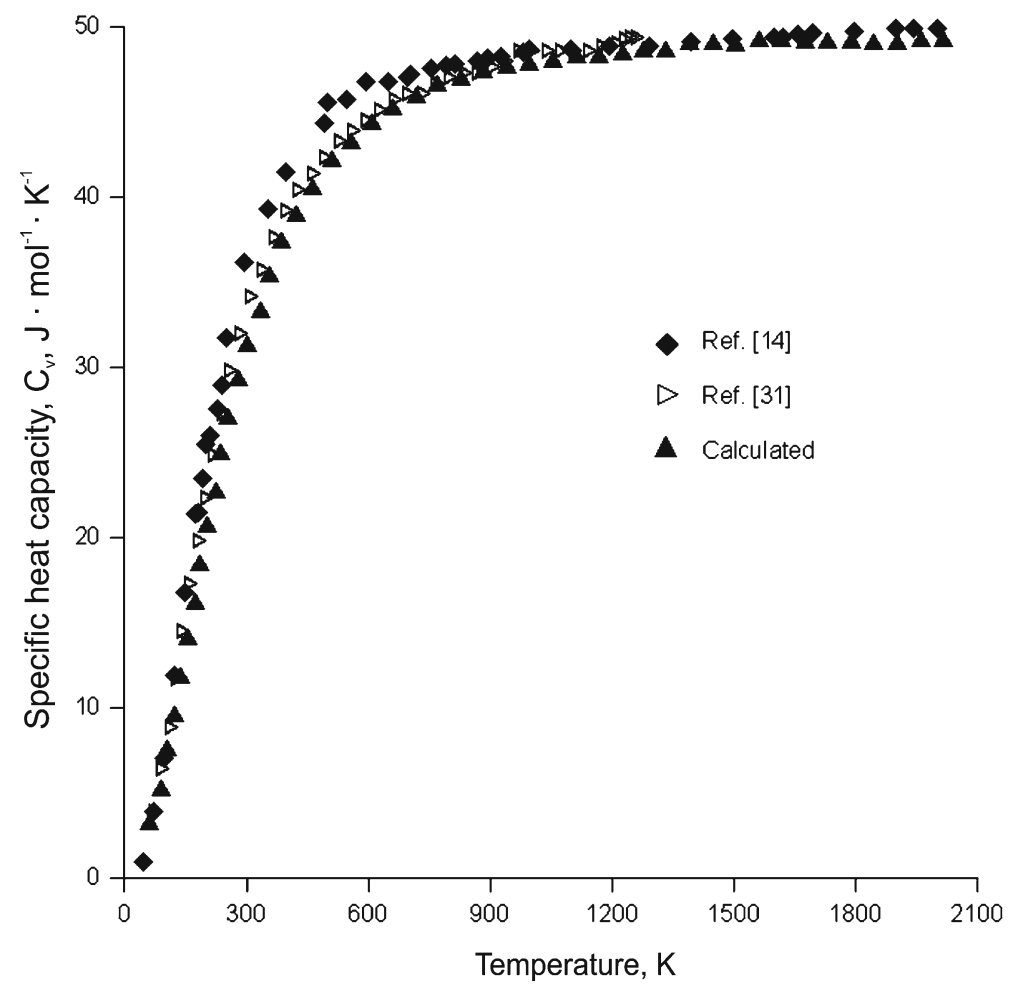

Fig. 1 Temperature dependence of heat capacity $C_{\mathrm{v}}$ for $\mathrm{MgO}$ crystals: Lu et al. [14]; Seko et al. [31]; "Calculated" 


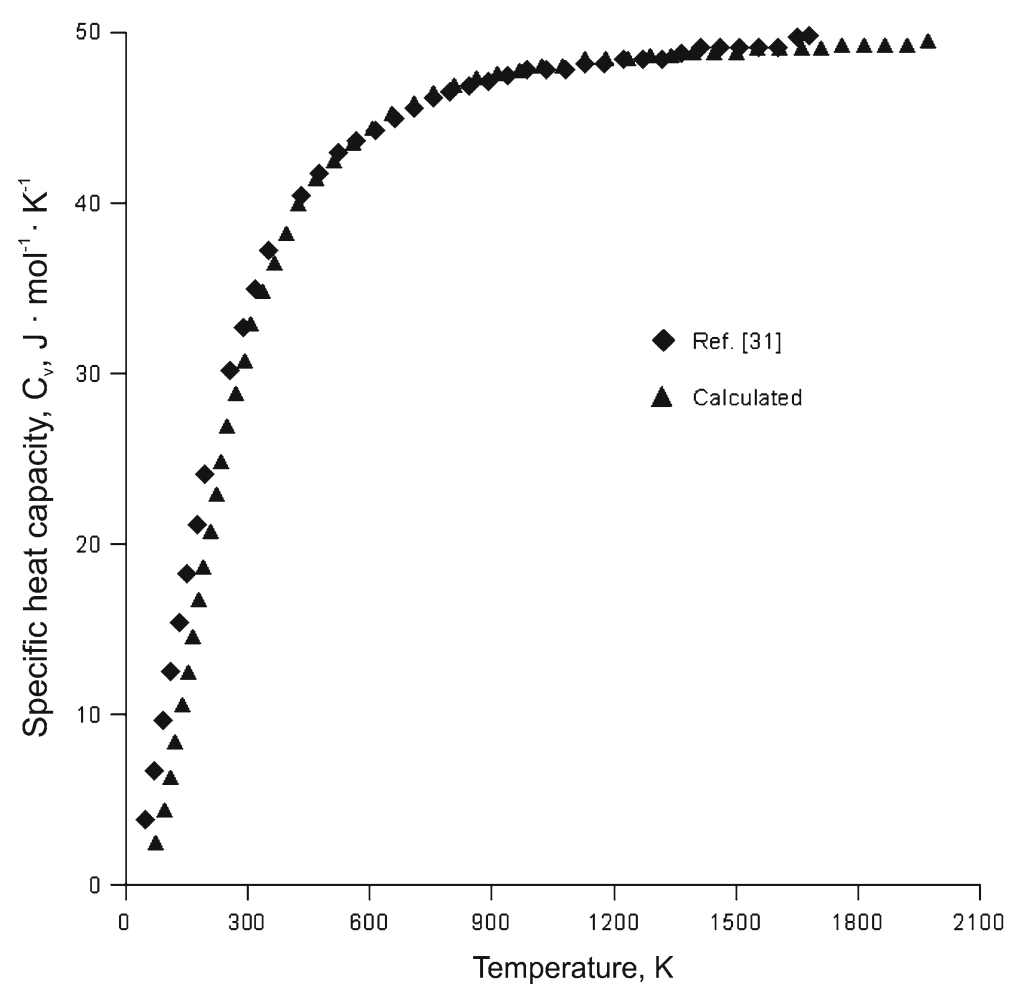

Fig. 2 Temperature dependence of heat capacity $C_{\mathrm{v}}$ for $\mathrm{ZnO}$ crystals: Seko et al. [31]; "Calculated"

In Fig. 2, we compare the results for $\mathrm{ZnO}$ crystals, which demonstrate excellent agreement between our results and those of Seko et al. [31] in the temperature range from $250 \mathrm{~K}$ to $1,800 \mathrm{~K}$.

In this study, an efficient and accurate method is presented for calculation of the heat capacity of a solid depending on the Debye temperature for all values of $m, s, n$, and $x_{\mathrm{D}}$. We are not aware of any previously published research undertaking calculation of Debye functions with $n, s, x_{\mathrm{D}}$, except for Ref. [13]. The use of the simple analytical expression for modeling and simulation can be useful in the development of high-quality devices and has wide fields of application.

In conclusion, we have presented a simple analytical expression for calculation of specific heat capacities of solids depending on Debye functions using binomial coefficients with all integer values of parameters $n, s$, and $x_{\mathrm{D}}$. The analytical expression obtained in this work can be used in the study of many physical problems, especially in the calculation of the heat capacity of solids. The use of the computer programs presented for calculation of $n$-dimensional Debye functions can be also used in the investigation of the quantum-mechanical behavior of phonons. We note that the derived expressions for the $n$-dimensional Debye functions can be evaluated efficiently, quickly, and accurately. 
Open Access This article is distributed under the terms of the Creative Commons Attribution Noncommercial License which permits any noncommercial use, distribution, and reproduction in any medium, provided the original author(s) and source are credited.

\section{References}

1. J.E. Mayer, M. Goeppert-Mayer, Statistical Mechanics (Wiley, New York, 1977)

2. A.A. Maradudin, E.W. Montroll, G.H. Weiss, Theory of Lattice Dynamics in the Harmonic Approximation (Academic Press, London, 1963)

3. H. Neumann, Cryst. Res. Technol. 39, 245 (2004)

4. C. Kittel, Introduction to Solid State Physics, 2nd edn. (Wiley \& Sons, Inc., New York, 1956)

5. G. Grimvall, Thermophysical Properties of Materials (North-Holland, Amsterdam, 1986)

6. V.V. Tarasov, Compt. Rend. Acad. Sci. URSS 46, 110 (1945)

7. W.H. Stockmayer, C.E. Hecht, J. Chem. Phys. 21, 1954 (1953)

8. M. Dole, Fortschr. Hochpol. Forsch. 2, 221 (1960)

9. M. Pyda, M. Bartkowiak, B. Wunderlich, J. Therm. Anal. Calorim. 52, 631 (1998)

10. S. Inaba, S. Oda, K. Morinaga, J. Non-Cryst. Solids 325, 258 (2003)

11. B. Wunderlich, J. Chem. Phys. 37, 1207 (1962)

12. U. Gaur, A. Mehta, B. Wunderlich, J. Thermal Anal. Calorim. 13, 71 (1978)

13. I.I. Guseinov, B.A. Mamedov, Int. J. Thermophys. 28, 1420 (2007)

14. L.-Y. Lu, Y. Chenga, X.-R. Chena, J. Zhu, Physica B 370, 236 (2005)

15. M.N. Magomedov, High Temp. 40, 542 (2002)

16. J. Avsec, M. Marcic, J. Thermophys. Heat Transfer 16, 463 (2002)

17. G. Chen, C.L. Tien, J. Thermophys. Heat Transfer 7, 311 (1993)

18. V. Eymet, A.M. Brasil, M. El Hafi, T.L. Farias, P.J. Coelho, JQSRT 74, 697 (2002)

19. S.I. Abu-Eishah, Int. J. Thermophys. 22, 1855 (2001)

20. I. Hatta, Thermochim. Acta 446, 176 (2006)

21. C.G. Windsor, R.N. Sinclair, Acta Cryst. A 32, 395 (1976)

22. T.L. Hill, Statistical Thermodynamics (Addison-Wesley, Reading, MA, 1960), p. 106

23. W. Nernst, A.F. Lindemann, Z. Elektrochem. Angew. Phys. Chem. 17, 817 (1911)

24. Y.S. Touloukian, E.H. Buyco, Thermophysical Properties of Matter, vol. 5, Specific Heat of Nonmetallic Solids (Plenum, New York, 1970)

25. C. Jasiukiewicz, V. Karpus, Solid State Commun. 128, 167 (2003)

26. A. Konti, Y.P. Varshni, Can. J. Phys. 47, 2021 (1969)

27. I.S. Gradshteyn, I.M. Ryzhik, Tables of Integrals, Sums, Series and Products, 4th edn. (Academic Press, New York, 1980), pp. 340-345; pp. 655-662

28. H. Kim, J.S. Horwitz, S.B. Qadri, D.B. Chrisey, Thin Solid Films 420, 107 (2002)

29. G.G. Gadzhiev, High Temp. 41, 778 (2003)

30. M.M. Mikhailov, V.V. Sharafutdinova, Russ. Phys. J. 40, 924 (1997)

31. A. Seko, F. Oba, A. Kuwabara, I. Tanaka, Phys. Rev. B 72, 024107 (2005)

32. J. Serrano, R.K. Kremer, M. Cardona, G. Siegle, A.H. Romero, R. Lauck, Phys. Rev. B 73, 094303 (2006)

33. S. Desgreniers, Phys. Rev. B 58, 21 (1998)

34. H. Karzel, W. Potzel, M. Kofferlein, W. Schiessl, M. Steiner, U. Hiller, G.M. Kalvius, D.W. Mitchell, T.P. Das, P. Blaha, K. Schwarz, M.P. Pasternak, Phys. Rev. B 53, 17 (1996)

35. X.W. Sun, Z.J. Liu, Q.F. Chenc, H.W. Lu, T. Song, C.W. Wang, Solid State Commun. 140, 219 (2006)

36. M. Abramowitz, I. Stegun, Handbook of Mathematical Functions (Dover, New York, 1972)

37. A.R. Hutson, J. Phys. Chem. Solids 8, 467 (1959)

38. S. Iida, K. Ohno, H. Kanzaki, H. Kumagai, S. Sawada, Butsuri-Jousuuhyou, Data Book for Physics (Asakura, Tokyo, 1969), pp. 89-92 [in Japanese] 